\title{
Modeling the Combined Effects of Credit Limit Management and Pricing Actions on Profitability of Credit Card Operations
}

\author{
Shubhamoy Dey \\ Indian Institute of Management \\ Prabandh Shikhar, Rau, Indore - 453331, India \\ Tel: 91-731-2439-526 E-mail: shubhamoy@iimidr.ac.in
}

\begin{abstract}
The profitability of any credit card portfolio is influenced by complex interactions between several conflicting factors like credit risk, probability of attrition, propensity to revolve, credit limit utilization and revenue generated. In this context, the allocation and maintenance of appropriate credit limits, and optimum pricing are the most critical parameters, as they affect a number of these factors. Going beyond previously reported work dealing with pricing and revenue optimization, and credit limit management in isolation, this paper proposes a method of studying the combined effects of credit limit management, and pricing actions on profitability using a system of empirical behavioral models for the individual factors; and discusses how simulation can be used to arrive at 'optimum' pricing and credit limit combinations for each credit card account in a portfolio.
\end{abstract}

Keywords: Empirical modeling, Credit risk, Profitability, Credit limit management, Credit pricing

\section{Introduction and Motivation}

Following the shock waves that were generated in the world economy dues to the subprime lending crisis, many commentators were of the opinion that a similar crisis involving credit card debt was imminent (e.g. Gumbel (2007), Silver-Greenberg (2008), Alston (2008), Dash (2008), and Ellis (2009)). This was possibly prompted by the fact that both delinquency and charge-off rates of credit card debt in United States have risen sharply since mid-2007 (as depicted in Figure-1), and the phenomenon has spread to countries other than the US (as evident from Figure-2). Though the total outstanding revolving credit (mostly credit card) balances in US was close to $\$ 900$ billion in 2009 (Federal Reserve Statistical Release - G.19 (2010)), and the ratio of credit card charge-offs to loan charge-offs have increased from $17.37 \%$ to $19.61 \%$ between the fourth quarter of 2008 (FDIC Quarterly Banking Profile (2008)) and the third quarter of 2009 (FDIC Quarterly Banking Profile (2009)), no serious crisis has emerged so far. In spite of that, the threat of such a crisis may not be unrealistic. Within this exceptionally challenging environment, as high charge-off rates tend to erode the profitability (and in some situations even the viability - e.g. HSBC Finance Corporation, Wachman (2009)) of credit card operations putting the system under further pressure, the importance of managing card credit limits and card pricing cannot be overstated. This work has been motivated by the notion that the development and application of innovative modeling techniques to predict the combined effects of these two primary parameters would provide a sound foundation to decision making in the area.

\section{Related Work}

Traditional credit scoring is an application of techniques from areas of statistics, operations research, and related disciplines like machine learning and data mining, that attempts to forecast financial risk associated with lending. It is essentially a way of distinguishing groups with different credit risk in a population, based on observed characteristics.

Though the concept of recognizing groups in a population was introduced in statistics by Fisher (1936), Durand (1941) was the first to propose that the technique could be used to distinguish between good and bad loans. The introduction of credit cards in the 1960s made automation of lending decisions a necessity and led to the realization of the usefulness of credit scoring. Since then there have been great advances in both techniques and applications of the concept of scoring. Discussion on the basics of credit scoring has been excluded from this paper, as such details can be found in text books like Thomas, Crook and Edelman (1992), Mays (1998), and Mays (2001). Much of the details of past research can be found in Rosenberg and Gleit (1994), Hand and Henley (1997), Thomas (2000), Thomas et. al (2005), Hu and Tang (2006), and Crook et. al (2007). More recent work 
on credit scoring have been reported by Chen et. al (2008), Yang and Duan (2008), Twala (2009), Lin (2009), Strokov (2009), Tebboth and Gadi (2009), Malik and Thomas (2009), and Dey (2009a).

Recently, the attention of researchers, as well as practitioners, has been drawn towards empirical modeling of various aspects of profitability as opposed to risk alone. This gradual maturing of the science of modeling within the practical world of credit operations is depicted in Figure-3 below.

The move towards optimization of credit strategies and the focus on profitability is also evident from the discussions appearing in academic literature. For example, Thomas et. al (2002) stress the importance of customer behaviour (apart from credit risk) such as likelihood of responding to a marketing campaign, likelihood of attrition, and propensity to revolve account balance in assessing profitability of an account. Stein (2005) studies the impact of score cut-offs of profitability and proposes a flexible pricing approach that is shown to be more profitable. Lariviere and Poel (2005) discuss the importance of customer retention and profitability prediction using random forest and regression forest techniques. They identify factors like 'next-buy' and defection (to rival products), and the 'evolution' of customers' profitability. Blochlinger and Leippold (2006) derive a profit-maximizing score cut-off and a pricing curve from the ROC curve of a scoring model. Seow and Thomas (2006) describe a method of attracting profitable customers by offering them appropriate credit products. Somers and Whittaker (2007) use quantile regression models to find distributions of profit and loss from a mortgage portfolio for various lending strategies. Sarlija et. al (2009) describe models to predict 'time to default' and discuss how it affects strategies related to profitability. Andreeva et. al (2007) present an empirical investigation of the relationship between revenue and time to default and time to second purchase. Their results indicate that there is scope for improving profit by incorporating time to default and time to second purchase (using survival probability scores) into credit application assessment, along with risk measures. Finlay (2009) stresses the importance of modeling continuous financial objectives of lenders like bad debt, revenue and profit. He uses a genetic algorithm based heuristic algorithm to optimize the profit contribution. His results show that such approaches identify profitable accounts more accurately compared to traditional default risk classification models. Wu and Hand (2007) highlight another aspect of the problem domain. Their work focuses on the modeling of the effects of certain account management actions like writing warning letters to customers who miss payments, on long term objectives like profit. They also attempt to address the inherent 'selection bias' of that type of models. Dey (2009b) proposes the use of a set of interacting models to study the effect of credit limit changes on profitability. Huang (2009) opines that, compared to a traditional modeling approach where a model or scorecard is developed as a generic and stand-alone tool for decision making, this type of 'action-effect' model suite development approach, will be more effective in ensuring a systematic, consistent, and integrated decision-making process. Businesses will benefit even though it takes more effort to design, define, and develop the models.

Phillips (2005) stresses the importance of 'Profit-based Pricing' of credit products. Drawing from the success of the concept in other industries like hotels, airlines, telecommunication and retail, he contends that financial services industry lags behind in thinking that 'Risk-based Pricing is the ultimate in pricing sophistication'. This is because risk-based pricing does not take into account customer price sensitivity. It is also pointed out that lenders in the financial services industry have a big advantage over firms in other industries like retail, as they have huge databases containing 'failed sales' information. Ten key points for successful implementation of profit-based pricing are proposed in the work. Another work in this area is by Renison and Hardt (2008). They discuss how price and revenue optimization in the context of the financial services industry is different from that of other industries, and demonstrate how historical failed sales data can be used to model price sensitivity. They also discuss the implications of risk and revenue on profitability.

It is evident from the discussion of previous work given above that credit risk, risk-based pricing, profit-based pricing, credit limits, and revolving balance changes affect profitability, and that none of these factors can be studied in isolation. This paper studies how actions, related to credit limit management and pricing of credit, taken on credit card accounts influence factors that are related to profitability, and proposes a 'composite action-effect' model to capture the complex interaction between those factors.

\section{Credit Limit Increase / Decrease Actions and Their Effects}

Though, Wu and Hand (2007) outline the importance of customer reaction to specific actions taken, their work concentrates on the aspect of selection bias. There is very little research work on modeling of the customer reactions to credit limit management actions taken by lenders reported in literature.

Lenders are motivated to take credit limit increase / decrease actions on credit card accounts due to a number of reasons. Credit limit decrease actions are taken primarily to reduce cost of Basel cost of RWA and potential 
losses. Excess unutilized credit limits increase RWA and blocks capital required. High unutilized credit limits in unused / infrequently used credit cards also increase the potential for fraud substantially. Behavioural models indicate that sudden increase in balances in generally unused credit cards are closely linked to financial hardship of the card holder - as credit limits on other cards run out and payment difficulties make new credit hard to obtain, limits on the unused cards are utilized leading to further aggravation of the situation. To keep LGD under control, it is also appropriate to decrease credit limits on accounts with low behaviour scores. It is therefore in the interest of the lenders to decrease the credit limits on certain types card accounts to the extent possible without prompting adverse reactions from the customers, or where the decrease is justified in spite of adverse customer reaction. On the other hand, an increase in credit limit would normally lead to increase in revolving credit balances and therefore increased revenue. Increasing credit limits can also increase customer loyalty and therefore customer lifetime value. However, limit increases have to be provided only to those accounts that are found 'eligible' under some criteria, and likely to utilize the increased limit to increase the revolving credit balances.

\section{Pricing Actions and Their Effects}

The economics of credit cards from the point of view of users as well as issuers has generated immense interest. Academics and practitioners alike have attempted to understand the dynamics behind credit card usage, and the costs and prices associated. The cost of credit card finance (to the consumer) has been traditionally perceived to be 'high', and has been the subject of a number of public policy debates. An article by Ausubel (1991) was one of the first to highlight that though the credit card market resembled a competitive one, the interest rates charged were high and 'sticky' downwards. Ausubel (1991) and others like Calem and Mester (1995), and Stango (2002) have attempted to address the apparent paradox based on asymmetry of information, search costs and switching costs. Another argument, put forward by Calem and Mester (1995), to explain the downward stickiness of interest rates, is that banks have an incentive not to unilaterally lower interest rates. Canner and Luckett (1992), and Cargill and Wendel (1996) argue that majority of card holders have little to gain by searching for lower rates because they are convenience users (i.e. those who repay the full card balance by due date) rather than borrowers (i.e. those who maintain a revolving balance and pay interest).

However, the competitive landscape changed starting form the early 1990s, possibly triggered by the lowering search costs and removal of asymmetry of information due to widespread adoption of the internet in key credit card markets like US and Europe. By 2002 interest rates came down by approximately five percentage points from the levels prevailing till 1991. During the same period, the previously ubiquitous annual fee on credit cards was almost eliminated. Much of these changes can be attributed to corrections of some of the 'imperfections' in the competitive market. Another very significant change was the shift away from risk-indifferent single (or at best a few) price structure(s) to risk-based pricing (Furletti (2003)). Risk-indifferent pricing (as discussed by Furletti (2003), Berlina and Mester (2004), and others) implies that low risk credit card users cross-subsidize the high risk ones. In the more competitive environment of the period following the late 1990s, this would lead to a problem known as 'adverse selection' (refer to Phillips and Raffard (2009), and Huang and Thomas (2009) for details) for card issuers who did not follow risk-based pricing. The move to risk based pricing and the loss of revenue due to discontinuance of annual fees, resulted in complex pricing structures. There are three main revenue streams in the credit card industry: viz, interest on revolving balances, various fees, interchanging charges on transactions. Out of the three, interchange charges are levied by card associations like Visa and MasterCard, and are shared between the 'acquirer', the card association and the 'issuer' as per agreed interchange rules. Interchange charges, sharing agreements, and how it affects card users and other consumers has its own line of debates and associated research, but as these charges do not come under the purview of card issuer pricing actions, they are beyond the scope of this work.

Interest on revolving balances is initially set based on the card features offered, fee structures associated and the risk profile of the applicant. However, the actual effective revenue can depend on a number of factors like 'introductory' rates on purchases and / or balance transfers, (typically higher) rates on cash / 'cash like' transactions, rules about how and when interest is calculated, and how payments are allocated to balances carried at different interest rates. Under risk-based pricing, the lender can revise interest rates (i.e. implement price change actions) of card users whose risk profiles change during the course of borrower-lender relationship.

After the elimination of fixed annual fees, which would have resulted in adverse selection, most card issuers have either revised some of the existing fees or introduced new fees to compensate the revenue lost. Fees form a substantial part of the revenue of credit card issuers, and can be a significant cost to some card users. While some fees are 'risk-related' fees, others are 'service-related' fees. Lender's risk models have revealed that borrowers who do not pay their bills on time, spend over their credit limits or do not have sufficient funds to 
support cheques they write, fall into a higher risk category than others. Cash and cash equivalent transactions carry high risk of fraud. Hence, fees like late fees, over-limit fees, bounced-cheque fees and cash advance charges are classed as risk-related fees. Other fees like those for statement copies and replacement cards are related to specific services, and are classed as service-related fees.

Card issuers package various 'features' and price structures to create a multitude of credit card 'products' to cater to customers with different usage patterns and perceived values. In the context of this paper, the effective rate(s) of interest and the fee structure for a particular product constitute the 'price' of that product. The cost incurred under this new complex pricing regime could vary greatly between different card users depending on their risk profile, usage pattern and the credit card product that is used. Also, as explained by Yang et. al (2007), users who change their usage pattern (from the expected usage pattern for which they had chosen an 'optimal' set of card features), face high costs due to the set of card features becoming 'sub-optimal' for the new usage pattern. This sub-optimality can also result from changes in pricing structure is effected by the lender (i.e. pricing actions taken) rather than changes in the borrower's usage pattern. In the current competitive environment, this implies a high likelihood of attrition. Thus, risk-based pricing can by no means be the ultimate in pricing, and to reach anywhere near optimality in credit card profitability many aspects need to be considered. Phillips (2005), for example, suggests ten key points. Among the most critical considerations are the effects of pricing on the revolving balances and probability of attrition.

Furthermore, the appropriate actions should ideally be determined for each individual 'eligible' account because firstly, the 'quantum' of the action (e.g. the amount by which the credit limit should be increased / decreased or the basis points by which the rate of interest should be increased / decreased) will depend on the profile of each eligible account, and secondly the reaction of each account holder is likely to be different. Thus, as shown in Figure-3 below, profit optimizing credit limit management strategies are oriented towards account level actions and account level profits.

\section{Modeling the Effects of the Actions}

The interactions between the variables that affect the target variable (i.e. profit) are complex. The Influence Diagram shown in Figure-4 below attempts to depict some of these. In this example three (input) variables: 'Behaviour Score', 'Utilization', and 'Propensity to Revolve' have been used to select the accounts eligible for the action. A simple cut-off value based criteria can be devised for the purpose. For example, accounts with behaviour scores below a certain threshold and utilization above a certain level (i.e. high risk accounts) can be chosen for credit limit decrease and / or interest rate increase action(s). Interest rate increase, in this case, would possibly be restricted to the accounts with high (i.e. above a threshold value) propensity to revolve because increasing interest rates on accounts of convenience users (rather than borrowers) will have little or no effect on revenue generated.

Most of the possible actions produce opposing effects, and the overall effect on the target variable depends on the strength of each of those opposing effects. For example, increase in credit limit has the desirable effect of increasing revenue, but at the same time both probability of default (i.e. P(Default) in Figure-4 below) and loss given default (LGD) are also increased. Similarly, decrease in credit limit, decreases expected loss but increases the probability of attrition (P(Attrition) in Figure-4) and leads to decrease in expected revenue. The overall effect and the appropriate action will depend on which of these effects is stronger.

The quantum of effects can be expected to have non-linear relationships with the action variables (as shown in Figure-5 below). Also, the direction of the overall effect may reverse beyond certain limits. For example, for a set of accounts with a particular set of characteristics, it might be profitable to increase credit limits up to a certain point beyond which the expected increase in revenue will not compensate the expected loss due to increased risk. The behaviour of each action-effect variable (viz.: 'Probability of Attrition', 'Probability of Default', 'Change in Balance', and 'Loss Given Default') are modeled separately and then the combined effect is studied by calculating the 'Expected Revenue', 'Expected Loss', and then 'Profit'.

The possible behaviour of one of the action-effect variables (attrition) with respect to the action (credit limit decrease, in this case) is depicted in Figure-5. The set of accounts for which these relationships are studied need to be similar to each other with respect to the other (control) variables (like risk - measured by the behaviour score). A series of such relationships (for different values of the control variables) constitute one 'action-effect model'. The relationships are derived from historical data of past champion / challenger testing of strategies, to the extent possible and then extrapolated (as shown in Figure-5).

The implementation of the action-effect system depicted in Figure-4 would require eight component empirical models: (i) Behaviour (risk) score, (ii) Propensity to revolve, (iii) Probability of attrition, (iv) Probability of 
default given non-attriter, (v) Loss given non-attriter and defaulter, (vi) Change in revolving balance given non-attriter and non-defaulter, (vii) Change in revenue against change in revolving balance, and (viii) Change in revenue against change in non-revolving balance. The modeling technique appropriate for each model would be determined by the nature of the data and relationships. For example, behavior score models are usually in the form of scorecards, while change in revenue against change in revolving balance models are usually a set of linear equations because for any given card account the applicable APR is constant at any one point in time. Since, attrition behaviour is dependant on a number of factors, probability of attrition can also be modeled as a scorecard. For constructing each component model the pre-requisite is the availability of enough data for the population sub-segment. For example, to construct model (vi) Change in revolving balance given non-attriter and non-defaulter, sufficient data (possibly from previous champion / challenger testing) would be required for the population sub-segment 'non-attriter and non-defaulter' for a number of combinations of credit limits and APRs. However, most credit card issuers have accumulated champion / challenger data over the years, enabling model construction (with the help of judicious extrapolation in some cases).

\section{Using the Model}

Ideally, an 'optimum' credit limit that leads to maximum profit could be derived for each account by 'simulating' the effect of increase / decrease actions over a range of action variable values. In practice this is approximated by applying 'simulation' to sets of similar accounts. For example, narrow range of values of the input variables can be used to divide accounts into sets for simulation. Thus, accounts within a narrow range of Behaviour Scores, Utilization and Propensity to Revolve would define sets of accounts, and simulation would be used to find the approximate 'optimum' credit limit and pricing combinations for each set of accounts. Increase / decrease action would then be taken to bring the credit limit and / or price associated with each account in a set to the optimum of that set.

\section{Conclusions and Further Work}

In this work a method of modeling the combined effect of actions pertaining to both quantity and price of credit (i.e. credit limit management and pricing) has been examined, and a way of using the model to set credit limits and prices of accounts consistent with the objective of maximizing profit has been discussed.

The 'theoretical' optima obtained by the process described in Section-6 above are valid only in the absence of business constraints. However, credit card lenders have to operate under various business constraints like resource limits, growth targets, bad debt limits, APR caps for market positioning, a minimum time interval between two consecutive APR changes to maintain stability, and a cap on the maximum price change allowed each time. The actions taken would become optimal in the business context only when the expected incremental profit is maximized under the given constraints. A way of introducing constraints into the model needs to be found.

As shown by $\mathrm{Wu}$ and Hand (2007) there is an inherent selection bias in models of this type, and since unlike the situation with reject inference described by Crook and Basnik (2004), the proportion of unselected cases are not small, the effect of the bias cannot be ignored. Pricing actions on individual accounts (i.e. the scenario investigated in this work) should have no effect on probability of default (as shown in Figure 4). However, if the price is set too high, over a period of time adverse selection would manifest itself through the attrition of accounts with low risk, thereby increasing the overall risk of the portfolio of accounts. Also, where champion / challenger data is not available, the model building requires extensive extrapolation. The validity of this has not been established. All these three aspects need to be investigated further.

\section{References}

Alston, J. (2008). The next phase: credit card crisis. [Online] Available: http://abclocal.go.com/kgo/story?section=news/business\&id=6061006 (January 31, 2010)

Andreeva, G., Ansell, J., \& Crook, J. (2007). Modelling profitability using survival combination scores, European Journal of Operational Research, 183, 1537-1549

Ausubel, L. (1991). The failure of competition in the credit card market. The American Economic Review, 81, 50-81

Berlina, M., \& Mester, L.J. (2004). Credit card rates and consumer search. Review of Financial Economics, 13, 179-198

Blochlinger, A., \& Leippold, M. (2006). Economic benefit of powerful credit scoring. Journal of Banking \& Finance, 30, 851-873 
Calem, P. S., \& Mester, L.J. (1995). Consumer behavior and the stickiness of credit-card interest rates. The American Economic Review, 85, 1327-1336

Canner, G.B., \& Luckett, C.A. (1992). Developments in the pricing of credit card services. Federal Reserve Bulletin, 78, 652-666

Cargill, T. F., \& Wendel, J. (1996). Bank credit cards: Consumer irrationality versus market forces. The Journal of Consumer Affairs, 30, 373-389

Chen, J., Pan, H., Han, Q., Chen, L., \& Ni, J. (2008). Credit Risk Assessment Model Based On Domain Knowledge Constraint. Proceedings of the 2008 International Multi-symposiums on Computer and Computational Sciences, Shanghai, China

Crook, J., \& Banasik, J. (2004). Does reject inference really improve the performance of application scoring models, Journal of Banking and Finance, 28, 857-874

Crook, J., Edelman, D. B., \& Thomas, L. C. (2007). Recent Developments in Consumer Credit Risk Assessment. European Journal of Operational Research, 183, 1447-1465

Dash, E. (2008). Consumers Feel the Next Crisis: It's credit Cards. [Online] Available: http://www.nytimes.com/2008/10/29/business/29credit.html (January 31, 2010)

Dey S. (2009a). A Two-stage Approach to Consumer Credit Scoring. Modeling and Analysis of Safety and Risk in Complex Systems / Proceedings of the Ninth International Scientific School, Saint-Petersburg, Russia

Dey, S. (2009b). Credit Limit Management using Action-effect Models. Proceedings of the 2009 International Conference on Financial Theory and Engineering, Dubai, UAE

Durand, D. (1941). Risk elements in consumer installment financing. New York: National Bureau of Economic Research

Ellis, D. (2009). Banks' future woes in one word: plastic. [Online] Available: http://money.cnn.com/2009/03/09/news/companies/banks_credit_cards/index.htm (January 31, 2010)

FDIC Quarterly Banking Profile. (2008). Composition of FDIC Insured Institutions' Loan Charge-offs. [Online] Available: http://www2.fdic.gov/qbp/toc.asp?rptdate=/qbp/2008dec\&htmfile=alltoc.html (January 31, 2010)

FDIC Quarterly Banking Profile. (2009). Composition of FDIC Insured Institutions' Loan Charge-offs. [Online] Available: http:/www2.fdic.gov/qbp/toc.asp?rptdate=/qbp/2009sep\&htmfile=alltoc.html\#AICQ (January 31, 2010)

Federal Reserve Statistical Release - G.19. (2010). Consumer Credit. [Online] Available: http://www.federalreserve.gov/releases/g19/Current/ (January 31, 2010)

Finlay, S. (2010). Credit scoring for profitability objectives. European Journal of Operational Research, 202, 528-537

Fisher, R. A. (1936). The use of multiple measurements in taxonomic problems. Annals of Eugenics, 7, 179-188

Furletti, M. J. (2003). Credit Card Pricing Developments and their Disclosure. Federal Reserve Bank of Philladelphia, Payment Cards Center. Discussion Paper No. 03-02. [Online] Available: http://ssrn.com/abstract $=572585$ or doi:10.2139/ssrn.572585

Gumbel, P. (2007). The \$915 Billion Bomb in Consumers' Wallets. [Online] Available: http://money.cnn.com/2007/10/29/magazines/fortune/consumer_debt.fortune/index.htm (January 31, 2010)

Hand, D. J., \& Henley, W. E. (1997). Statistical classification methods in consumer credit. Journal of the Royal Statistical Society, Series A, 160, 523-541

Hu, X., \& Tang, Y. (2006). ANN-Based Credit Risk Identification and Control for Commercial Banks. Proceedings of the Fifth International Conference on Machine Learning and Cybernetics, Dalian, China

Huang, B., \& Thomas, L.C. (2009). Credit card pricing and impact of adverse selection. Proceedings of Credit Scoring Conference - XI, Edinburgh, UK

Huang, E. X. M. (2009). Decision Science in Retail Banking: Innovation at Work. The Capco Institute Journal of Financial Transformation, 23, 115-120.

Larivière, B., \& Poel, V.D. (2005). Predicting customer retention and profitability by using random forests and regression forests techniques. Expert Systems with Applications, 29, 472-484 
Lin, S.L. (2009). A new two-stage hybrid approach of credit risk in banking industry. Expert Systems with Applications, 36, 8333-8341

Malik, M., \& Thomas, L.C. (2009). Modelling credit risk in portfolios of consumer loans: Transition Matrix Model for Consumer Credit Ratings. Proceedings of Credit Scoring Conference - XI, Edinburgh, UK

Mays, E. (1998). Credit risk modeling. Chicago: Glenlake Publishing

Mays, E. (2001). Handbook of Credit scoring. New York: American Management Association

Phillips, R., \& Raffard, R. (2009). Theory and Empirical Evidence for Price-Driven Adverse Selection in Consumer Lending. Proceedings of Credit Scoring Conference - XI, Edinburgh, UK

Phillips, R. (2005). Pricing and Revenue Optimization. Stanford: Stanford University Press

Renison, K., \& Hardt, L. (2008). Price and Revenue Optimization for Banking. Proceedings of the SAS Global Forum 2008, San Antonio, Texas, USA

Rosenberg, E., \& Gleit, A. (1994). Quantitative methods in credit management: a survey. Operations Research, 42, 589-613

Sarlija, N., Bensic, M., \& Zekic-Susac, M. (2009). Comparison procedure of predicting the time to default in behavioural scoring, Expert Systems with Applications, 36, 8778-8788

Seow, H., \& Thomas, L. C. (2006). Using adaptive learning in credit scoring to estimate take-up probability distribution. European Journal of Operational Research, 173, 880-892

Silver-Greenberg, J. (2008). The Next Meltdown: Credit-Card Debt. [Online] Available: http://www.businessweek.com/magazine/content/08_42/b4104024799703.htm (January 31, 2010)

Somers, M., \& Whittaker, J. (2007). Quantile regression for modelling distributions of profit and loss. European Journal of Operational Research, 183, 1477-1487

Stango, V. (2002). Pricing with consumer switching costs: Evidence from the credit card market. Journal of Industrial Economics, 50, 475-92

Stein, R. M. (2005). The relationship between default prediction and lending profits: Integrating ROC analysis and loan pricing. Journal of Banking \& Finance, 29, 1213-1236

Strokov D. S. (2009). Criteria of Identification of LP-Models of Credit Risk under Statistical Data. Modeling and Analysis of Safety and Risk in Complex Systems / Proceedings of the Ninth International Scientific School, Saint-Petersburg, Russia

Tebboth, J., \& Gadi, M. (2009). Assessing the use of indeterminates for scorecard model development. Proceedings of Credit Scoring Conference - XI, Edinburgh, UK

Thomas, L. C. (2000). A survey of credit and behavioural scoring: forecasting financial risk of lending to consumers. International Journal of Forecasting, 16, 149-172

Thomas, L. C., Crook, J. N., \& Edelman, D. B. (1992). Credit scoring and credit control. Oxford: Oxford University Press

Thomas, L.C., Edelman, D.B., \& Crook, J.N. (2002). Credit Scoring and its Applications. Philadelphia: Siam

Thomas, L.C., Oliver, R.W., \& Hand, D.J. (2005). A survey of the issues in consumer credit modelling research. Journal of the Operational Research Society, 56, 1006-1015

Twala, B. (2010). Multiple classifier application to credit risk assessment. Expert Systems with Applications, 37 , 3326-3336

Wachman, R. (2009). HSBC faces crisis over US credit cards. [Online] Available: http://www.guardian.co.uk/money/2009/apr/12/hsbc-credit-cards-us-business (January 31, 2010)

Wu, I., Hand \& D. J. (2007). Handling selection bias when choosing actions in retail credit applications. European Journal of Operational Research, 183, 1560-1568

Yang, C., \& Duan, X. (2008). Credit Risk Assessment in Commercial Banks based on SVM using PCA. Proceedings of the Seventh International Conference on Machine Learning and Cybernetics, Kunming, China

Yang, S., Markoczy, L., \& Min, Q. (2007). Unrealistic optimism in consumer credit card adoption. Journal of Economic Psychology, 28, 170-185. 
Charge-off rates Delinquency rates

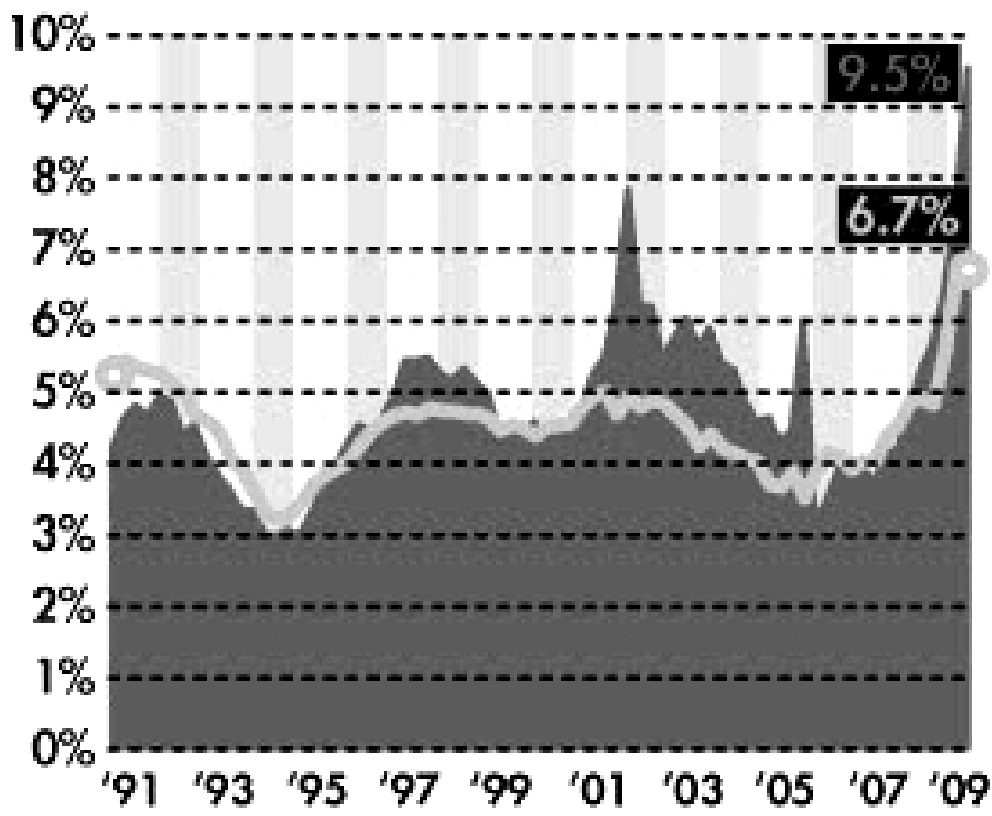

Source: The Federal Reserve

Figure 1. Credit Card Delinquency and Charge-off Rates in United States

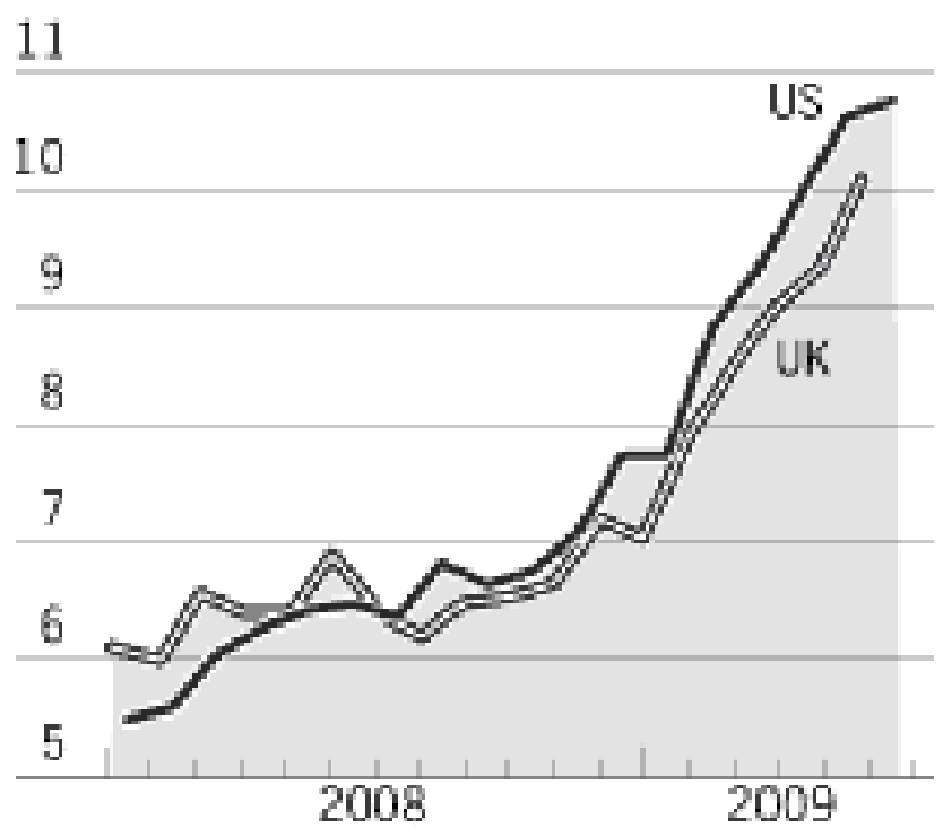

Source: Moody's Credit Card Indices: Oliver Wyman

Figure 2. Credit Card Charge-off Rates in US and UK 


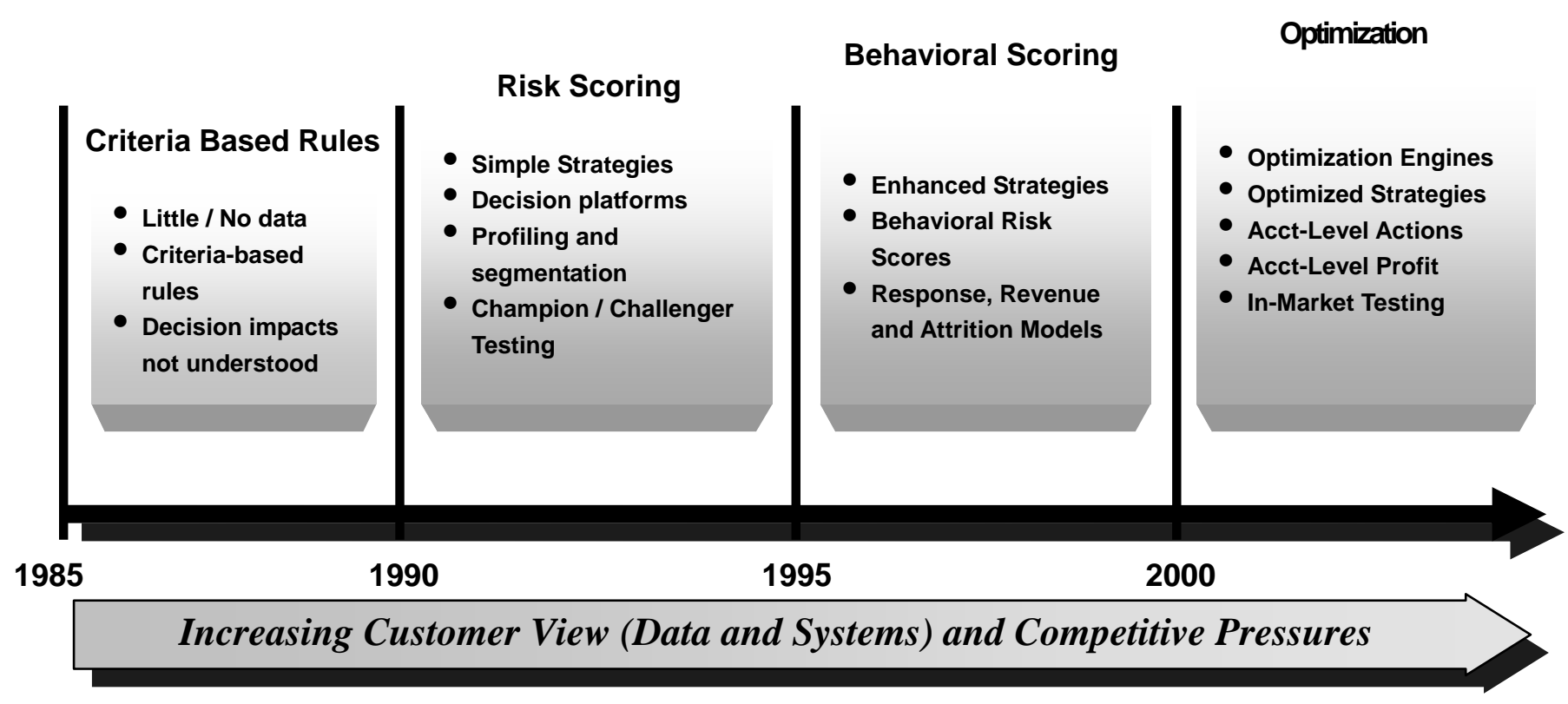

Figure 3. The move from Credit Scoring to Profit Optimization
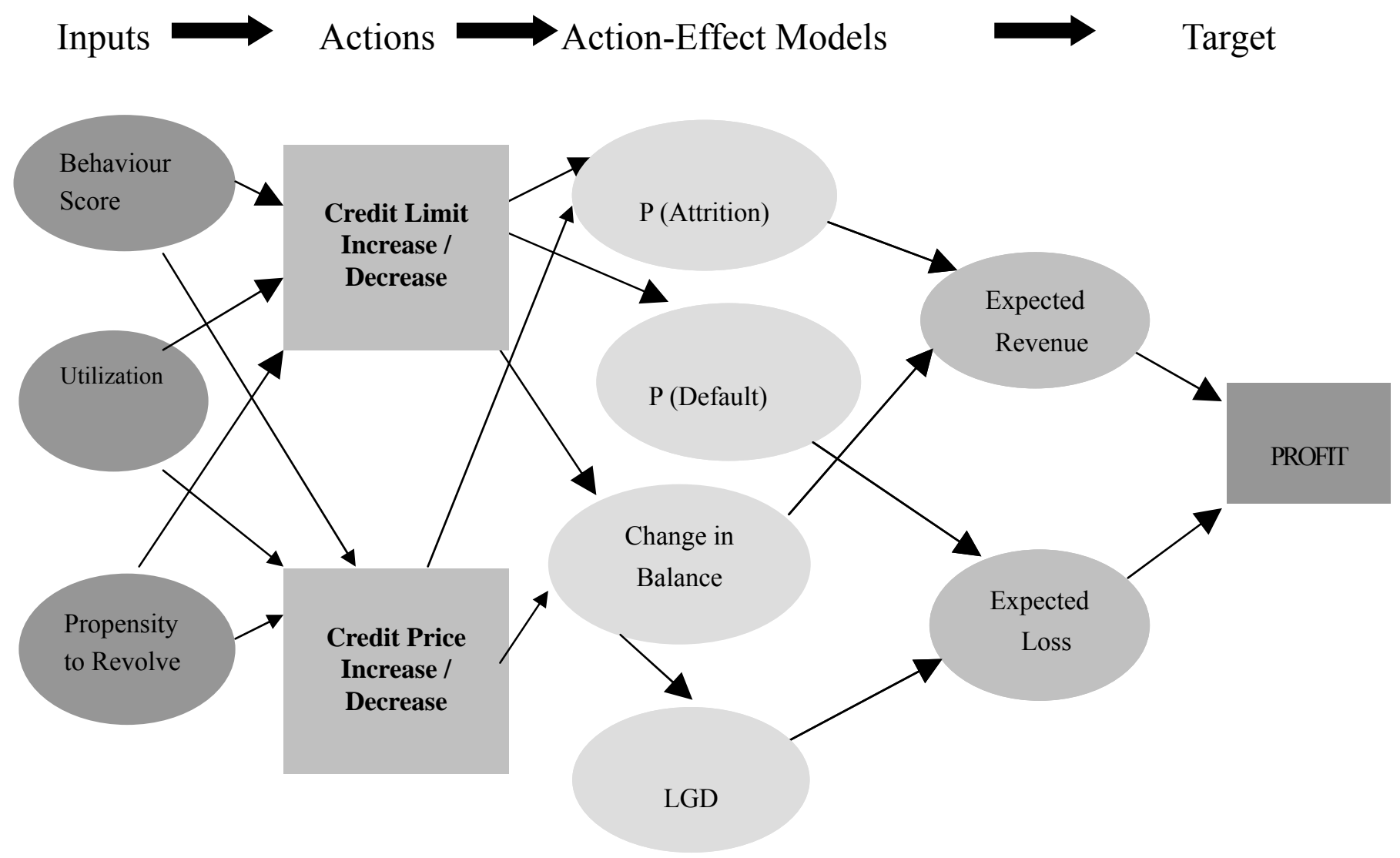

Figure 4. Influence Diagram showing Action-effect Models 


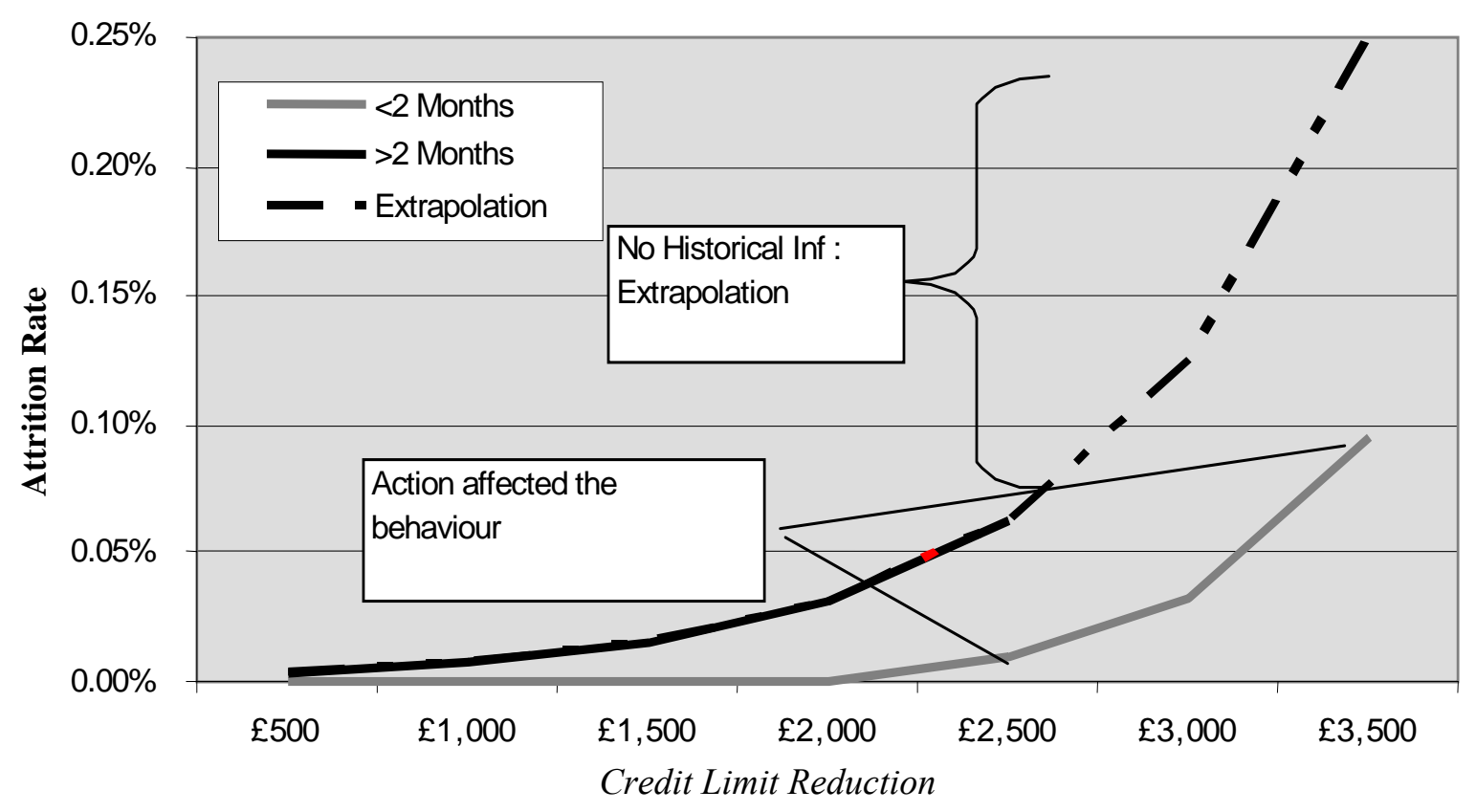

Figure 5. Hypothetical Action-effect Behaviour of Attrition 